\title{
EFFECTIVENESS OF TOPICAL HYALURONIC ACID VERSUS CHLORHEXIDINE MOUTHWASHES IN THE TREATMENT OF RECURRENT APHTHOUS STOMATITIS: A RANDOMIZED CLINICAL TRIAL
}

\author{
Mai Zakaria*, Amira Abdelwhab ${ }^{* *}$ and Sandy Shaaban Hassan ${ }^{* * *}$
}

\begin{abstract}
Background: Recurrent aphthous stomatitis (RAS) is the most common disorder affecting oral mucosa. The present study was designed to assess the clinical effectiveness of utilizing topical hyaluronic acid (HA) against chlorhexidine (CHX) mouthwashes as a control in RAS treatment.
\end{abstract}

Materials and methods: Thirty-four patients with minor RAS were included in the trial. They were equally allocated into two groups with random distribution to rinse with CHX mouthwash as a control (Group I, CHX Group) and HA mouthwash in (Group II, HA group) as a study group. Evaluation of pain intensity and ulcer size were done in all study patients at baseline, 3 days and 7 days observational times. Duration of healing period was assessed in both study groups.

Results: The results demonstrated a significant lowering in pain score and ulcer size in each group. Lower mean values of these outcomes were recorded in HA group compared to CHX group at 3 days and 7 days with significant difference regarding pain score. Concerning the duration of healing a significant decrease was recorded in HA group compared to CHX group.

Conclusion: In conclusion, topical HA is a safe and effective treatment option for RAS with better pain control and healing duration.

KEY WORDS: recurrent aphthous stomatitis, chlorhexidine, hyaluronic acid, healing, pain.

\section{INTRODUCTION}

Recurrent aphthous stomatitis (RAS) is the most common known disease affecting mucosa of the oral cavity. It arises usually in the form of single or multiple distinct self-limiting ulcers surrounded by erythema involving the nonkeratinized oral mucosa and associated with pain ${ }^{[1]}$. The RAS prevalence is $25 \%$ worldwide with $50 \%$ as a frequency of recurrence each 3 months. The precise reason of

\footnotetext{
* Oral Medicine and Periodontology Department, Faculty of Dentistry, Cairo University, Egypt

** Oral Medicine Department, Faculty of Dentistry, October 6th University, Egypt

*** Oral Medicine and Periodontology Department, Faculty of Dentistry, Fayoum University, Egypt
} 
RAS is undefined consequently several factors are so far being involved for instance genetic, hormonal, traumatic, nutritional, allergic, immunological, and psychological mechanisms ${ }^{[2,3]}$.

RAS is classified into minor, major, and herpetiform forms. Furthermore, the minor type comprises $85 \%$ of RAS patients, where ulcerative lesions not exceed $1 \mathrm{~cm}$ in diameter and healing occurs without scarring ${ }^{[4]}$. RAS produces problems in food intake, speech, deglutition, and the tongue movement, which reduces the patient's quality of life and undesirably affects the somatic and psychological measures of personal satisfaction ${ }^{[5]}$.

Since no definite cause of RAS has been known, RAS treatment is not specific and is intended just for decreasing symptoms ${ }^{[6]}$. The frequently existing medicines include topical anesthetic, antimicrobial mouthwashes, and immunosuppressive or antiinflammatory medications in the topical and systemic form with recognized unwanted effects ${ }^{[2]}$.

Hyaluronan or hyaluronic acid (HA) is a biological material that has been presented as an alternate substitute to improve wound healing process ${ }^{[7]}$. HA is a main carbohydrate constituent of the extracellular matrix and presents in numerous tissues ${ }^{[8]}$. In the RAS treatment, HA quickly diminish the pain and anxiety produced by the ulcers, stimulates the healing course, and considerably decrease the recurrence rate of the disease. Furthermore, it regulates the inflammatory reaction and enhances the tissues rehydration ${ }^{[9]}$. Chlorhexidine ( $\mathrm{CHX})$ is considered as one of the furthermost commonly suggested medication for management of oral ulcers ${ }^{[10]}$.

For that reason, the current study was conducted to evaluate the clinical efficacy of topical hyaluronic acid versus CHX mouthwashes in the treatment of minor recurrent aphthous stomatitis.

\section{MATERIALS AND METHODS}

\section{Ethical approval}

The present study was carried out in accordance with the World Medical Association guidelines of ethics (Declaration of Helsinki, 1978, as revised in 2008) for studies including human contributors. The trial protocol was permitted by Ethical Committee of the Faculty of Dentistry, Cairo University with Code no 191225. In addition, it was registered in the Clinical Trials.gov with NCT04265001. Ahead to beginning the trial; an informed consent was signed up by all the patients later to complete description of the study procedures.

\section{Sample Size Calculation}

Using of $\mathrm{G}^{*}$ power software the appropriate sample size was designed with one- tailed test in relation to the results of the earlier trial by Koray et al., ${ }^{[11]}$. In view of that $\alpha=0.05$; power at 0.8 ; allocation ratio $(1: 1)$ and the effect size $=0.98$. Therefore, the sample size was 34 patients to overcome any lessening that might occur by reason of patients' taking away.

\section{Patients}

This study is a randomized controlled clinical trial. A total number of 34 patients with minor RAS were involved, who presented at the Oral Medicine and Periodontology Department, Faculty of Dentistry, Cairo University. The RAS diagnosis was done depending on the patient's history and thorough clinical examination ${ }^{[12]}$.

\section{Inclusion and exclusion criteria}

The inclusion criteria were patients 18 -30 years old with minor RAS for less than 48 hours in simply reachable region of the oral cavity, having at least 2 years history of recurrence.

The exclusion criteria were as follows; recognized history of allergies to $\mathrm{CHX}$ or $\mathrm{HA}$; smoking intake and systemic diseases for instance 
Behçet disease, anemia, ulcerative colitis, Crohn's disease, acquired immune deficiency syndrome, and renal or liver disorders. Besides, treatment with systemic nonsteroidal anti-inflammatory agents, systemic steroids, vitamins, antihistamines, antibiotics or other immune modulatory drugs three months prior to study entrance.

\section{Study design}

The included 34 patients were randomly allocated into 2 equal groups through preoperative envelope drawing. In group I (CHX group; $n=17$ ) patients rinsed with CHX hydrochloride $125 \mathrm{mg} / 100 \mathrm{ml}$ (Hexitol; Arab Drug Company for Pharmaceutical and Chemical Industries, Cairo, Egypt) mouthwash as a control group. Meanwhile in group II (HA group; $\mathrm{n}=17$ ) patients rinsed with hyaluronan sodium $25 \mathrm{mg} / 100 \mathrm{ml}$ (Aftamed; Bioplaxpharma, UK).

All the study participants were instructed to rinse $10 \mathrm{ml}$ of the recommended mouth wash for 30 seconds three times daily for seven days and to report any unwanted effects. Patients were not allowed for eating or drinking for a minimum of 1 hour after mouthwash usage. The patients were not allowed to use any medication for their ulcers except the recommended one. The participants masking regarding the recommended treatment couldn't be done owing to noticeable difference in color among the two commercially existing mouthwashes used in the study.

\section{Clinical evaluation}

All the study participants groups were assessed for pain score, ulcer size and duration of healing. The ulcer that took place last of all ulcers if multiple ones presented, was considered for assessment. Pain score was done after the ulcer irritation by the periodontal probe, using a visual analog scale (VAS). It consists of straight line with $10-\mathrm{cm}$ length between its ends, with 0 denoting no pain and 10 for intolerable pain ${ }^{[13]}$. The ulcer size was assessed by defining the length between two opposite borders of the edge through a periodontal probe in millimeters ${ }^{[14]}$. These outcomes were measured at the first visit before beginning of treatment (baseline), 3 days, and 7 days by one of the trial authors who was masked about the recommended medication utilized. The ulcer healing durations was recorded as a periods needed for complete healing in days.

\section{Statistical analysis}

Data were analyzed by SPSS version 25 (IBM Corp., Armonk, NY, USA). The statistician was masked concerning the modalities described in the contemplate groups. Mean and standard deviation were used for quantitative variables and frequencies while relative frequencies were used for categorical variables. Comparisons between groups were conducted by unpaired $t$ test in normally distributed quantitative variables while non-parametric Mann-Whitney test was used for non-normally distributed quantitative variables. For comparison of serial measurements within each group the nonparametric Friedman test and Wilcoxon signed rank test were used. For comparing categorical data, Chi square $\left(\mathrm{c}^{2}\right)$ test was performed. Exact test was used instead when the expected frequency was less than 5. P-values less than 0.05 were considered as statistically significant.

\section{RESULTS}

This study was conducted on 34 patients with minor RAS. The gender was 13 male and 21 female, with age range between 18 to 30 years (mean age: $23.08 \pm 3.54$ years) (Table 1$)$. All the study patients accomplished the trial without any withdrawal.

In this research, HA group patients didn't record any unwanted reactions. However, one patient in CHX group presented with change in taste sensation.

In relation to the baseline data of age and gender, there was no statistical difference between the CHX 
group and HA group (Table 1). Additionally, there was no significant difference recorded between the two study groups as regards pain score and ulcer size $(\mathrm{P}=0.892,0.973)$ respectively (Table 2,3$)$.

TABLE (1) Demographic records of the study participants.

\begin{tabular}{|c|c|c|c|c|}
\hline \multirow{2}{*}{\multicolumn{2}{|c|}{ Count $(\%)$}} & $\begin{array}{c}\text { Group I } \\
\text { (CHX group) }\end{array}$ & $\begin{array}{c}\text { Group II } \\
\text { (HA group) }\end{array}$ & \multirow[t]{2}{*}{ P value } \\
\hline & & \multicolumn{2}{|l|}{ Count $(\%)$} & \\
\hline \multirow{2}{*}{$\begin{array}{c}\text { Gender } \\
\left(\chi^{2}\right)\end{array}$} & $\mathbf{M}$ & $7(41.2 \%)$ & $6(35.3 \%)$ & \multirow{2}{*}{$0.724^{\mathrm{ns}}$} \\
\hline & $\mathbf{F}$ & $10(58.8 \%)$ & $11(64.7 \%)$ & \\
\hline \multicolumn{2}{|c|}{$\begin{array}{l}\text { Age (t-test) } \\
(\text { mean } \pm \text { SD })\end{array}$} & $22.88 \pm 3.64$ & $23.29 \pm 3.44$ & $0.737^{\mathrm{ns}}$ \\
\hline
\end{tabular}

Significance at $p<0.05 ; S D=$ standard deviation; $n s=$ non-significant.

In respect to pain score, there was a statistically significant decrease in both CHX group and HA group $(\mathrm{p}<0.001)$ over 3 days and 7 days from baseline values. Comparison between the two study groups exhibited a decreased mean values recorded in the HA group with significant differences at 3 days and 7 days $(P=0.029,0.006)$ respectively (Table 2, Figure 1).

Table (2) Comparison of pain score records at several intervals of observation in the same group by Friedman test and between the two study groups by Mann-Whitney test.

\begin{tabular}{|c|c|c|c|}
\hline Group & $\begin{array}{c}\text { Group } \\
\text { I (CHX } \\
\text { group) } \\
\text { (Mean } \pm \text { SD) }\end{array}$ & $\begin{array}{c}\text { Group II } \\
\text { (HA group) } \\
\text { (Mean } \pm \\
\text { SD) }\end{array}$ & $\begin{array}{l}\text { P value } \\
\text { between the } \\
\text { 2 groups }\end{array}$ \\
\hline $\begin{array}{c}\text { Pain score } \\
\text { (Baseline) }\end{array}$ & $6.35 \pm 1.17$ & $6.41 \pm 1.37$ & 0.892 \\
\hline $\begin{array}{c}\text { Pain score } \\
\text { (3 days) }\end{array}$ & $3.53 \pm 1.07$ & $2.71 \pm 0.77$ & $0.029 *$ \\
\hline $\begin{array}{c}\text { Pain score } \\
\text { (7 days) }\end{array}$ & $1.53 \pm 0.80$ & $0.71 \pm 0.69$ & $0.006^{*}$ \\
\hline $\begin{array}{c}\text { P value } \\
\text { overtime }\end{array}$ & $<0.001 * *$ & $<0.001 * *$ & - \\
\hline
\end{tabular}

$S D=$ standard deviation ; *Significant difference than control at $P<0.05$; ${ }^{* *}$ Significant difference compared baseline at $P<0.05$.
In respect to ulcer size, there was a statistically significant decrease in both CHX group and HA group ( $\mathrm{p}<0.001$ ) over 3 days and 7 days from baseline values. Comparison between the two study groups exhibited a decreased mean values recorded in the HA group but not reached the level of significance at 3 days and 7 days $(\mathrm{P}=0.057)$ (Table 3 , Figure 2). In respect of duration of healing, there was a statistically significant lower period showed in HA group compared to $\mathrm{CHX}$ group $(\mathrm{p}<0.001)$ (Table 4).

TABLE (3) Comparison of ulcer size records at several intervals of observation in the same group by Friedman test and between the two study groups by Mann-Whitney test.

\begin{tabular}{|c|c|c|c|}
\hline Group & $\begin{array}{c}\text { Group } \\
\text { I (CHX } \\
\text { group) } \\
\text { (Mean } \pm \text { SD) }\end{array}$ & $\begin{array}{c}\text { Group II } \\
\text { (HA group) } \\
\text { (Mean } \pm \text { SD) }\end{array}$ & $\begin{array}{c}\text { P value } \\
\text { between } \\
\text { the 2 } \\
\text { groups }\end{array}$ \\
\hline $\begin{array}{c}\text { Ulcer size } \\
\text { (Base line) }\end{array}$ & $6.12 \pm 1.22$ & $6.12 \pm 1.17$ & 0.973 \\
\hline $\begin{array}{c}\text { Ulcer size (3 } \\
\text { days) }\end{array}$ & $3.94 \pm 1.14$ & $3.18 \pm 0.81$ & 0.057 \\
\hline $\begin{array}{c}\text { Ulcer size (7 } \\
\text { days) }\end{array}$ & $1.76 \pm 0.83$ & $1.18 \pm 0.73$ & 0.057 \\
\hline $\begin{array}{c}\text { P value } \\
\text { overtime }\end{array}$ & $<0.001 * *$ & $<0.001 * *$ & - \\
\hline
\end{tabular}

**Significant difference compared baseline at $P<0.05$. SD = standard deviation.

TABLE (4) Comparison of healing period between the two study groups by independent sample t-test.

\begin{tabular}{|c|c|c|c|}
\hline Group & $\begin{array}{c}\text { Group } \\
\text { I (CHX } \\
\text { group) } \\
\text { Mean } \pm \text { SD) }\end{array}$ & $\begin{array}{c}\text { Group II } \\
\text { (HA group) } \\
\text { (Mean } \pm \text { SD) }\end{array}$ & P value \\
\hline $\begin{array}{c}\text { Healing } \\
\text { duration }\end{array}$ & $6.53 \pm 1.07$ & $4.53 \pm 0.80$ & $<0.001^{*}$ \\
\hline
\end{tabular}

$S D=$ standard deviation; *Significant difference than control at $\mathbf{P}<0.05$. 


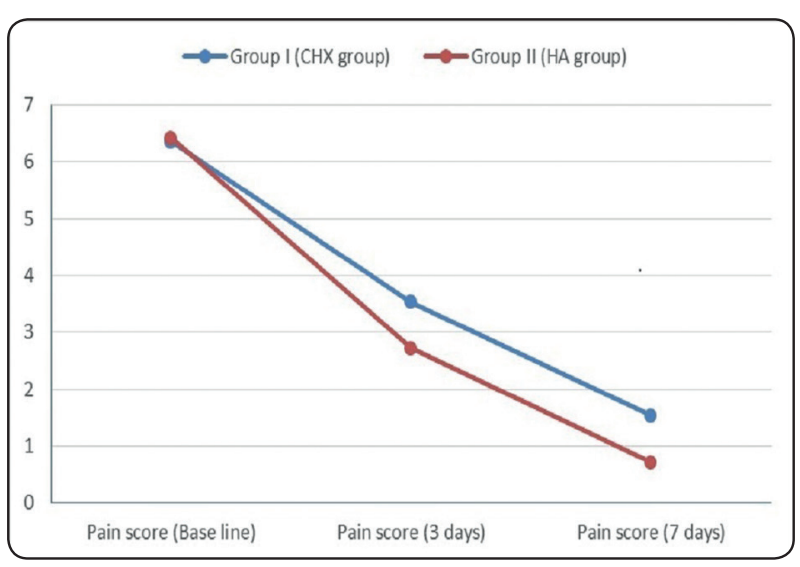

Fig. (1) Presenting the mean pain score records at baseline, 3 days, and 7 days intervals in the two study groups.

\section{DISCUSSION}

RAS is an ulcerative disease characterized by recurrence and self-limiting nature with commonly 7-10 days interval; though, it produces remarkable pain and discomfort consequently negatively affecting the satisfaction of patient concerning his/ her life ${ }^{[15]}$. Therefore, the primary objective of the treatment is to lessen the accompanying pain and discomfort, decline of the recurrence rate, and the enhancing of healing mechanism ${ }^{[16]}$. HA is a substitute material for treatment of RAS topically. It is a glycosaminoglycan has anti-inflammatory and antiedematous properties. HA possess complex characters in biology, using together its physicochemical and biological activities. Similarly it has numerous characteristics that consider it a possibly best element for enhancing wound healing, prompting useful initial granulation tissue development, preventing negative inflammatory process throughout the healing period, stimulating re-epithelialization process and angiogenesis ${ }^{[11]}$.

In view of that, this trial was done to investigate the efficacy of topical hyaluronic acid versus CHX as mouthwashes in the treatment of minor RAS regarding the grade of pain, ulcer size and healing duration. To the authors' knowledge, the current research is the first one compares between HA and

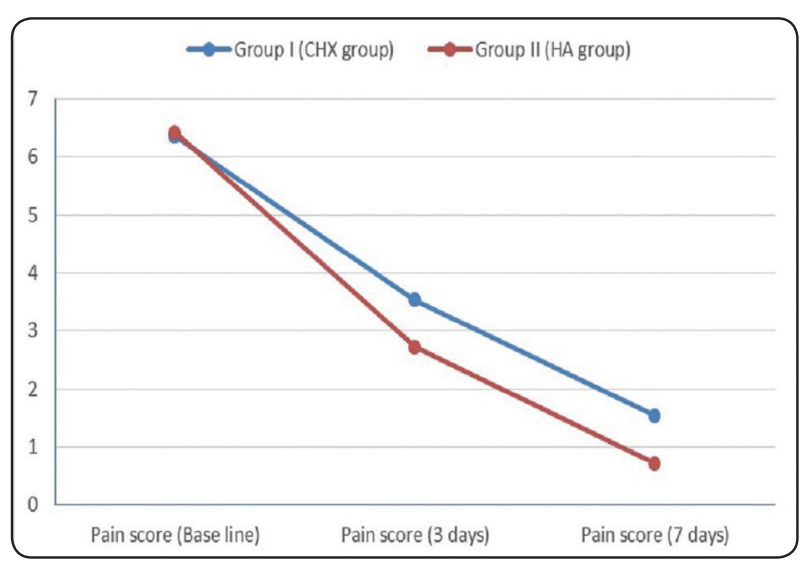

Fig. (2) Presenting the mean ulcer size records at baseline, 3days, and 7 days intervals in the two study groups.

CHX for the RAS treatment in a randomized clinical trial design.

The results of current contemplate indicated that one patient in CHX group presented with change in taste sensation. This occurred as documented side effect of CHX use. Furthermore formation of calculus, staining of teeth and toxic effect on cells as undesirable reactions that decrease the use of $\mathrm{CHX}$ as a regular mouthwash ${ }^{[17]}$.

The results of the present contemplate indicated that regarding the pain score and ulcer size there was significant decrease with the same group at 3 days and 7 days. Also there were lower mean values in HA group when compared to $\mathrm{CHX}$ group which were statistically significant concerning the pain score but not significant in respect to ulcer size at 3 days and 7 days observational times. Similarly, lower significant mean values were recorded in HA group in comparison with $\mathrm{CHX}$ group about the duration healing periods. These findings may be elucidated by that CHX may be a treatment of RAS owing to its ability to decrease the occurrence of secondary infection however it can't induce noteworthy rapid pain control following its usage ${ }^{[18]}$.

The findings discovered by the current study were in agreement with the results of the previous research which found that a significant decrease of 
pain score values for RAS in both HA group using HA gel and triamcinolone acetonide (TA) group using 0.1 TA gel for one week, and a lower significant difference in HA group compared to TA group at 4 days and 7 days intervals ${ }^{[11]}$. Besides another earlier study results which indicated that significant decrease in the pain intensity and healing period in RAS group after topical use of 0.2 HA in gel form for 2 weeks but when compared to Behçet's disease induced oral ulcers group there was no significant difference between the two groups ${ }^{[9]}$. Moreover, additional trial showed higher significant difference in pain level change and healing duration in CHX group rinsed with $\mathrm{CHX}$ mouth wash compared to sucralfate group rinsed with sucralfate suspension for one week 4 times daily as a treatment for RAS ${ }^{[10]}$. Another recent retrospective clinical study reported that significant reduction in pain score and ulcer size of RAS in both study groups using HA in mouth rise form and topical gel form respectively three times daily for one week ${ }^{[19]}$.

The findings reported from the current study were against the previous trial results showed that equally topical HA and placebo gel use caused a significant lessening in ulcer pain next direct use while during the coming study duration there were no significant differences among both treatments groups aimed at decreasing pain ${ }^{[18]}$. The explanation may be due to the difference of HA form and concentration which where 0.2 gel in the mentioned trial and mouthwash form in the present research. Besides, the placebo gel may have a protective or barrier activity.

The explanation of the present contemplate findings is that topical use of HA in the form of mouthwash employs its stimulating activities on wound healing through enhancing new collagen and blood vessels formation. Angiogenesis raises the oxygen supply and supplementary elements which are essential for collagen production locally which exerts a crucial effect for wound healing [11]. Likewise, HA in the form of sodium hyaluronate which was used in the present study covers the oral mucosa, facilitating hydration of the tissues and stimulates the healing process ${ }^{[20]}$.

\section{Conflicts of interest}

There are no conflicts of interest.

\section{Financial support and sponsorship}

Nil.

\section{CONCLUSION}

As a result, topical HA mouthwash is effective and safe treatment modality for RAS in terms of pain control, decrease of ulcer dimension and faster wound healing period.

\section{REFERENCES}

1. Rathee M, Bhoria M, Boora P. Recurrent aphthous stomatitis: an overview. Int J Fam Pract 2014; 13:1-6.

2. Tarakji B, Gazal G, Al-Maweri SA, Azzeghaiby SN, Alaizari N. Guideline for the diagnosis and treatment of recurrent aphthous stomatitis for dental practitioners. J Int Oral Health 2015; 7:74-80.

3. Vaziri S, Mojarrab M, Farzaei MH, Najafi F, Ghobadi A. Evaluation of antiaphthous activity of decoction of Nicotianatabacum leaves as a mouthwash: a placebo-controlled clinical study. J Tradit Chin Med 2016; 15:160-164.

4. Akintoye SO, Greenberg MS. Recurrent aphthous stomatitis. Dent Clin North Am 2014; 58:281-297.

5. Altenburg A, Zouboulis CC. Current concepts in the treatment of recurrent aphthous stomatitis. Skin Therapy Lett 2008; 13:1-4.

6. Altenburg A, Abdel-Naser MB, Seeber H, Abdallah M, Zouboulis CC. Practical aspects of management of recurrent aphthous stomatitis. J Eur Acad Dermatol Venereol 2007; 21:1019-1026.

7. Hammad HM, Hammad MM, Abdelhadi IN, Khalifeh MS. Effects of topically applied agents on intra-oral wound healing in a rat model: a clinical and histomorphometric study. Int J Dent Hyg 2011; 9(1): 9-16.

8. Chen WY, Abatangelo G. Functions of hyaluronan in wound repair. Wound Repair Regen 1999; 7(2): 79-89. 
9. Lee JH, Jung JY, Bang D. The efficacy of topical $0.2 \%$ hyaluronic acid gel on recurrent oral ulcers: comparison between recurrent aphthous ulcers and the oral ulcers of Behçet's disease. J Eur Acad Dermatol Venereol 2008; 22(5): 590-595.

10. Soylu Özler G, Okuyucu Ş, Akoğlu E.The Efficacy of Sucralfate and Chlorhexidine as an Oral Rinse in Patients with Recurrent Aphthous Stomatitis. Adv Med. 2014;2014:986203.

11. Koray M, Ofluoglu D, Senemtasi A, İşsever H, Yaltirik M. The Efficacy of Hyaluronic Acid Gel in Pain Control of Recurrent Aphthous Stomatitis. Int J Dentistry Oral Sci. 2016; 3(6), 273-275.

12. Tarakji B, Gazal G, Al-Maweri SA, Azzeghaiby SN, Alaizari N. Guideline for the diagnosis and treatment of recurrent aphthous stomatitis for dental practitioners. J Int Oral Health 2015; 7:74-80.

13. Wewers ME, Lowe NK. A critical review of visual analogue scales in the measurement of clinical phenomena. Res Nurs Health 1990; 13:227-236.

14. Liu J, Zeng X, Chen Q, et al. An evaluation on the efficacy and safety of amlexanox oral adhesive tablets in the treatment of recurrent minor aphthous ulceration in a Chinese cohort: a randomized, double-blind, vehicle-controlled, unparallel multicenter clinical trial. Oral Surg Oral Med Oral Pathol Oral Radiol Endod 20 06; 102:475-481.
15. Vaziri S, Mojarrab M, Farzaei MH, Najafi F, Ghobadi A. Evaluation of antiaphthous activity of decoction of Nicotianatabacum leaves as a mouthwash: a placebo-controlled clinical study. J Tradit Chin Med 2016; 15:160-164.

16. Vijayabala GS, Kalappanavar AN, Annigeri RG, Sudarshan R, Shettar SS. Single application of topical doxycycline hyclate in the management of recurrent aphthous stomatitis. Oral Med 2013; 16:440-446.

17. Pourshahidi S, Rezazadeh F, Motamedifar M, Davarmanesh M, Ebrahimi H, Alipour A. In vitro comparative study on antiherpetic effect of chlorhexidine and persica mouthwashes with acyclovir. J Basic Appl Sci. 2012; 8:286-290.

18. Nolan A1, Baillie C, Badminton J, Rudralingham M, Seymour RA. The efficacy of topical hyaluronic acid in the management of recurrent aphthous ulceration. J Oral Pathol Med. 2006;35(8):461-5

19. Dalessandri D, Zotti F, Laffranchi L, Migliorati M, Isola G, Bonetti S, Visconti L. Treatment of recurrent aphthous stomatitis (RAS; aphthae; canker sores) with a barrier forming mouth rinse or topical gel formulation containing hyaluronic acid: a retrospective clinical study. BMC Oral Health. 2019;19(1):153.

20. Kapoor P, Sachdeva S, Sachdeva S. Topical hyaluronic Acid in the management of oral ulcers. Indian J Dermatol. 2011;56(3):300-2. 